\title{
The Impacts of Media Ecology on the Perceptions of a Virtual Community called @PandemicTalk
}

\author{
Riris Tiani $^{1 *}$, Afidhatul Latifah ${ }^{2}$, Fadhila Mazida ${ }^{3}$ \\ ${ }^{1}$ Faculty of Humanities, Diponegoro University, Semarang - Indonesia \\ ${ }^{2}$ Faculty of Humanities, Diponegoro University, Semarang - Indonesia \\ ${ }^{3}$ Faculty of Humanities, Diponegoro University, Semarang - Indonesia
}

\begin{abstract}
The development of technology changes the ways humans communicate. The presence Instagram brings various solutions and makes communication easier and faster for people throughout the world. In last two years during outbreak of COVID-19, humans dominantly used digital power to perform all life activities. Digital information related to COVID-19 was recorded in virtual community called@Pandemictalk. @Pandemictalk a virtual community focusing on development Covid-19 information in Indonesia. Development of information related to COVID-19 was controlled and monitored by government. The purpose of study to determine ecological impacts media on the people's perceptions in understanding the digital information. Research data were obtained using natnographic method. After identified, data then interpreted using a descriptive contextual method. The results this study reveal that media ecology has a positive correlation with dissemination information related to COVID-19 on @ Pandemictalk. Media ecology shapes people's lifestyle increasingly dependent on electronics. This dependence is interpreted as ecological electronic mass. Virtual communication is more effective in processing people's perceptions reflected in the infographics concepts which are easier to perceive. The visual verbal message contents strictly implement the health protocols and information based on local and central government regulations related to community social assistance and religious information.
\end{abstract}

\section{Introduction}

Human Human life is greatly influenced by technology. The significant influence makes society dependent on technology, especially communication technology. Humans have symbiotic relationships reflected in technology. Humans cannot live without technology. Humans create technology. The world of digital technology will, in due time, create a new civilization for humans, media ecology. The media ecology can perceive human thinking [1]. 
The bases of thinking in the media ecology domain are, first, media is involved in each act in the society. Media is not conceived as an item that can be held, such as television, radio, or magazine. Media must be conceived as framing used for social phenomena imaging which involves humans. Second, media may serve to control the perception of social experience obtained. Third, media directly influences humans. Media will dominantly influence the ways humans appraise. Thus media plays a vital role in shaping human framing of the world [1]. Effects and shifts described in news consumption behaviours are mostly related to the changes made by the media ecology [2].

With the development of technology, physical documents slowly started to be abandoned, shifting to paperless. In line with digital advancement in its growing process, all parts of the world have a cultural shock as the impacts of change to the new life order popularly called the new normal. New normal is a culture arising from compulsion. Society is not ready, but a country also has cultural shock as the controller of life regulation. The digital technology just introduced in Indonesia recently suddenly becomes advice that the society must master. Some people could adapt to the new normal in technology, but many people were massively left and even left behind because of their non-adaptability.

One form of digital technology was realized in social media networking. Social media improved its function to be a new inspiring, entertaining world with the opportunity to improve the economy elegantly. Social media currently serves to disseminate influencing, entertaining and educating information in society [3]. Digital technology provides information that can be seen and listened to by users. The development of digital technology influences how to communicate and interact; consequently, the language used to communicate changes [4]. This includes the communication pattern in the case of the development of Covid-19 information in social media. The dilemma in the Covid-19 pandemic condition was that the society was required to do their life activities in complete limitation for social distancing. Even many governments and private institutions, and residences applied lockdown. With such a public emergency, social media massively contributed to framing information or news about self-and social experience accurately and widely [5]. The social media which became the government's partner in disseminating information about Covid-19 includes Instagram @Pandemictalk. This stud tried to reveal the perception of digital society of framing of information at @Pandemictalk

\section{Research Method}

This qualitative study employed a netnography method for the accuracy of data in social media. Analyzing the problems was based on the media ecology approach as the foundation to explore and understand the meaning of verbal and visual messages regarding social symptoms and phenomena appropriately [6]. The data were limited to verbal and visual messages in the account @pandemictalk and were collected through purposive random sampling. After the data were obtained with indicators of data with a bias of information regarding some societal phenomena, the data were analyzed using the descriptive phenomenological method. The analysis results were the society's comprehensive perception of the verbal and visual messages in account @Pandemictalk. 


\section{Result and Discussion}

\subsection{Media as the Regulator of People's Acts}

Instagram account@Pandemictalk serves as one of the accounts facilitated by the government to give updates on the development of information related to Covid-19 globally. In the account, there are verbal and visual messages:

\section{"Kemendikbud: Tetap Buka Sekolah di Juli 2021 meski IDAI tak setuju”}

"Indonesian Ministry of education and culture: Keep opening schools in July 2021 even though IDAI doesn't agree."

The perception built in the digital society in understanding the verbal message 'Keep opening schools in July 2021 even though IDAI does not agree' was that the Indonesian Ministry of Education and Culture did not build a symbiotic relationship with the Indonesian Ministry of Health. This is apparent in the policy issued. Covid-19 cases in Indonesia are still fluctuating, and it is still not declared as a green zone by WHO. On the other hand, the Indonesian Ministry of Education and Culture made a statement and technical regulations concerning the implementation of education in 2021 that the implementation of direct, face-to-face school education had been applied despite being technically limited. The statement contradicts IDAI's statement that it did not agree with the policy issued by the Indonesian Ministry of Education and Culture.

The digital society as the ones to receive information of digital space in social media was at a disadvantage. The digital society is individual and collective, in this case, school institutions and local government. The condition of Covid-19 spread in every district in Indonesia was different. Therefore, interpreting the central government's policy (Indonesian Ministry of Education and Culture) should also adapt to the condition of the respective district. These adaptations involved local government and school institutions and student's guardians and students as the subject of education. Policies issued by the government might potentially cause non-acceptance by some students' guardians or parents, particularly in the district declared as a red zone.

Some private schools also felt unfair policies. Face-to-face school implementation may potentially become a cluster of Covid-19 spread. On the other hand, not all parents could provide device facilities as the primary medium of school online, although each school assisted with internet quotes to each student. When school online is forced, the logical consequence received by the school was that parents would cease to fund their child's education.

Covid-19 indeed affects all levels of society and even the earth ecology. Social distancing becomes the solution taken along with all restrictions of social activities. If it is mandatory to implement face-to-face school simultaneously, the school can apply greenspace facilities. Students take courses in green open spaces. Modern urban greenspace facilities can be partially viewed as the planning outcome of cities' response to previous crises and pandemics [7].

\subsection{Media As the Control of Perception of Social Experience}

Change to digital technology makes most people in various parts of the world have cultural shock, including Indonesia. As the supporting facility to spread information, social media plays the leading role in shaping human's social experience. Unfortunately, not all of the government's policies delivered through social media can be understood 
correctly by the digital community, which is apparent in the following visual and verbal message:

“Kemenpar: Mudik Tidak Boleh, Wisata Lokal Boleh!”

Indonesian Ministry of Tourism: Homecoming Is Not Allowed, Local Tourism Is Allowed!

Indonesian Ministry of Tourism's content of the verbal message: Homecoming Is Not Allowed, Local Tourism Is Allowed! Builds a social perception of the government's nonseriousness in enforcing social distancing. Homecoming (known as Mudik) is a crossreligion communal tradition in Indonesia. This activity takes place once a year when Eid al-Fitr is about to come. Virtual visits replaced the prohibition of religious rituals. That the government prohibited homecoming is entirely appropriate when the world is facing Covid-19 pandemic. The prohibition quite effectively held down the dissemination of Covid-19.

On the other hand, however, the government loosened the rule that is going to a tourist attraction is allowed. Contradictory rules formed the society's perception that the handling of prevention of Covid-19 spread was not serious. Such perception became the reason that certain people kept doing homecoming to their hometown. The homecoming flow was even quite heavy before the government applied the rule of prohibition from doing homecoming.

The media plays a significant role in building perceptions in society. Many media use this opportunity to convey information that is not real. This causes mass panic in the community. The limited social space makes people use the internet more or social media to support activities. Social space restrictions seriously impact mental health, so many people experience psychological disorders, frustration, and even stress [8].

\subsection{Media as the Facilitator of Unity}

Media as the facilitator plays a very important role in realizing the national integration. National integration is quite vital, especially in the face of international outbreak of Covid-19. Maintaining national stability and harmony becomes one of social media's responsibilities, as presented in figure 1.

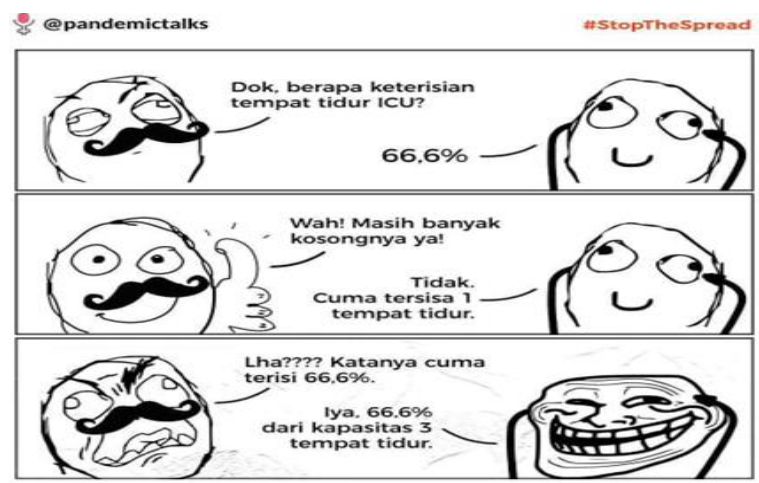

Fig1. Verbal Messages on Instagram as a Facilitator of Unity.

Source: @Pandemictalk 
Infographic message reflecting the function of media as the one to unify perception of digital information is apparent in Figure 1, A: he said only $66.6 \%$ was filled. B: Yes, $66.6 \%$ of the capacity of 3 beds. The verbal message formed the perception of a digital society that the Covid-19 pandemic was indeed a deadly outbreak, while the preparedness of hospitals in Indonesia to provide isolation rooms was limited. It was proven by the fact that all isolation rooms in various hospitals were only a few. The other perception of digital society in defining the verbal message was that the Covid-19 issue is a shared problem, thus for social harmonization, one must tolerate and be empathize with each other. Social assistance in the form of money or basic needs flowed rapidly and was distributed to those in need. The assistance was from the society and the form of selffinancing from individuals in the community with an economic surplus. Therefore, media has the power to create unity and social harmonization in the digital society environment.

Without government intervention, media development is like a sharp knife. Overall, digital media has led to an unstable interregnum, where news producers sell information according to current business opportunities [9]. Digital media can also be used as a force for destruction. Destroyer of trust, to destroyer of community culture [8]. Therefore, the government still has to control the flow of information in digital media fully. The government must guarantee that the information submitted to the public has a total value of information sharpness [10].

\section{Conclusion}

Media connects the world. Media forms political and economic powers. Thus it changes the social function in the society. This social function is replaced by a digital social function which spreads massively until ecology is formed. Media ecology positively correlates with the dissemination of information on Covid-19 di @Pandemictalk. Media ecology forms the society's lifestyle that is increasingly dependent on electronics. This dependence is defined as a period of electronic ecology. Virtual communication more effectively processes others' perceptions. This is reflected in an infographic concept that is easier to understand well. The visual and verbal messages contain the express application of health protocol, local and central government regulations related to social assistance, and religious information. The government must be an evaluator of the flow of information in digital media. The government must ensure the accuracy of the information obtained by the public. People's interpersonal impulses have a reciprocal interaction with digital media as information providers. Therefore, in providing information to the digital media community, the government must pay attention to aspects of the cultural ecosystem service.

\section{References}

[1] Batubara, Abdul Karim. Media Ecology Theory. Jurnal IQRA', Volume 08 No.02. (2014)

[2] Struckmann, Samson and Karnowski. News Consumption in a Changing Media Ecology: An MESM Study on Mobile News. (2015).

https://dx.doi.org/10.1016/j.tele.2015.08.012

[3] Damayanti, Annisa. Instagram as a Risk Communication Medium during the COVID-19 Pandemic: A Study Netnography of the KawalCOVID19.id Online Community. (2020) https://doi.org/doi 10.46937/18202032355 
[4] Natsir, Muhammad, et al. Language Change in Social Media (Instagram). (2020). https://doi.org/10.47175/rissj.v1i2.70

[5] Islam, A. K. M. N., Laato, S., Talukder, S., \& Sutinen, E. (2020). Misinformation sharing and social media fatigue during COVID-19: An affordance and cognitive load perspective. Technological Forecasting and Social Change. (2020). https://doi.org/10.1016/j.techfore.2020.12.201

[6] Creswell, J.W. Research Design Approaches to Qualitative, Quantitative and Mixed Methods ( $4^{\text {th }}$ revision). Pustaka Pelajar. (2013)

[7] Yi Lu, et al. Escaping to Nature During A Pandemic: A Natural Experiment in Asian Cities During The Covid 19 Pandemic with Big Social Media Data. (2021). https://doi.org/10.1016/j.scitotenv2021.146092

[8] Chaturvedi, Kunal, et.al. COVID-19 and its impact on education, social life and mental health of students: A survey. (2021) https://doi.org.proxy.undip.ac.id/10.1016/j.childyouth.2020.105866

[9] Tufekci, Zayneb. Social Movements And Governments In The Digital Age: Evaluating A Complex Landscape. (2014) https://www.jstor.org/stable/24461703

[10] Calcagni, Fulvia, et.al. Digital co-construction of relational values: understanding the role of social media for sustainability. (2018).

https://proquest.proxy.undip.ac.id/docview/2188501311/FF5E58D745B54416PQ/4?acc ountid $=49069$ 